\title{
Effective population-wide public health interventions to promote sodium reduction
}

\author{
Sailesh Mohan MD MPH, Norm R.C. Campbell MD, Kevin Willis PhD
}

Previously published at www.cmaj.ca

$\mathrm{E}$ levated blood pressure is an important risk factor for cardiovascular disease, which accounts for about 7.6 million deaths, or $13.5 \%$ of deaths, annually worldwide. ${ }^{1}$ High dietary sodium has been associated with an increase in blood pressure, hypertension, direct vascular and cardiac damage, obesity, stomach cancer, osteoporosis, kidney stones and increased severity of asthma symptoms. ${ }^{2}$ In Canada, reducing sodium consumption to the recommended levels would likely decrease the prevalence of hypertension by $30 \%$, reduce hypertension-related cardiovascular events by $8.6 \%$ and save about 2 billion dollars annually in health care costs even without considering the impact of other sodium-related health risks. ${ }^{3}$ Health care professionals worldwide, including in Canada, have played important roles in reducing dietary sodium.

Although disease-based approaches to caring for individuals at high risk of cardiovascular disease are important, they are resource-intensive and ultimately benefit few patients. In contrast, a population-wide reduction in sodium intake could prevent a large proportion of cardiovascular events in both normotensive and hypertensive populations. For example, a population-wide decrease of $2 \mathrm{~mm} \mathrm{Hg}$ diastolic blood pressure would be estimated to lower the prevalence of hypertension by $17 \%$, coronary artery disease by $6 \%$ and the risk of stroke by $15 \%$, with many of the benefits occurring among patients with normal blood pressure. ${ }^{4}$

In this article, we review the evidence related to dietary sodium and health in the context of the Ottawa Charter for Health Promotion, ${ }^{5}$ an internationally adopted framework for health organizations to advocate health promotion. We searched MEDLINE (January 1980 to December 2008) for peerreviewed literature on sodium and sodium-reduction strategies. To identify appropriate literature related to the major themes of the Ottawa Charter, we used search terms such as sodium, salt, population sodium-reduction strategies, population sodium or salt interventions, sodium or salt policies, community action for sodium or salt reduction, healthy food choices and role of health system. We searched the identified articles for additional studies of interest. To obtain grey literature and reports, we screened Google Scholar and the websites of the World Health Organiza$\vec{\sigma}$ tion (WHO) and other relevant health organizations.

\section{Impact of excess sodium consumption}

Worldwide, nearly 1 billion adults have hypertension, and $17 \%-30 \%$ of hypertension can be attributed to excess dietary sodium. ${ }^{6,7}$ Large reductions in cardiovascular disease have

\section{Key points}

- Excess dietary sodium is an important contributor to high blood pressure.

- Physicians and other health care professionals need to play an important role in sodium reduction.

- Population-based public health interventions to lower sodium intake and blood pressure are feasible and cost effective.

- Governments, food industry, health and scientific organizations need to work in partnership to achieve sodium reduction.

been observed in controlled intervention studies ${ }^{8,9}$ and in Finland after implementation of initiatives for sodium reduction. ${ }^{10} \mathrm{~A}$ recent analysis showed that 8.5 million deaths worldwide could be avoided over 10 years (2006-2015) by population initiatives to reduce dietary sodium. ${ }^{11}$

Hypertension awareness, treatment and control rates are suboptimal in Canada, where hypertension is the most common diagnosis that leads to physician visits. ${ }^{12}$ Although lifestyle modification is effective in lowering blood pressure, few patients with hypertension implement lifestyle changes. ${ }^{13}$ Sodium reduction is probably the most feasible lifestyle intervention, in part because it can be implemented without substantive change in societal structure or consumer behaviour. ${ }^{14}$ Furthermore, the average daily sodium intake in Canada is more than double the highest recommended level. ${ }^{15}$

\section{Sodium-reduction policies and strategies}

The WHO recommends a daily sodium intake of $2000 \mathrm{mg}$ or less. ${ }^{16}$ The current goal of the UK government is $2400 \mathrm{mg} / \mathrm{d}$ or less. In the United States and Canada, the Institute of Medicine has set an "upper tolerable intake" level for most adults of $2300 \mathrm{mg} / \mathrm{d} .{ }^{17,18}$ Dose-response calculations support a further reduction to $1200 \mathrm{mg} / \mathrm{d} .{ }^{19}$ In Canada, the Dietary Reference Intakes for "adequate sodium intake" range from $1000 \mathrm{mg} / \mathrm{d}$ sodium for people aged 1-3 years to $1500 \mathrm{mg} / \mathrm{d}$ sodium for those aged $9-50 . .^{18}$ To achieve these goals, national public-health policies are focusing on reformulating

From the Departments of Medicine, Community Health Sciences, Physiology and Pharmacology, and the Libin Cardiovascular Institute (Mohan, Campbell), University of Calgary, Calgary Alta.; and the Canadian Stroke Network (Willis), Ottawa, Ont.

Cite as CMAJ 2009. DOI:10.1503/cmaj.090361 
Box 1: Effective strategies to reduce sodium consumption

- Partnership with and regulation of the food industry

- Reformulation of processed foods

- Targeted consumer education about the effects of excess dietary sodium on health

- Consumer-friendly food labelling to identify low-sodium products

- Increased access and availability of low-sodium foods

processed foods, educating consumers, improving food labelling and increasing the availability of low-sodium food products. Given that almost $80 \%$ of sodium intake is from processed foods in most developed countries, ${ }^{20}$ collaboration with and regulation of the food industry are critical for achieving change (Box 1).

\section{Regulation of the food industry}

Finland, a country that uses a regulatory approach, provides one of the best examples of population reductions in sodium intake (Table 1). Since the early 1970s, Finland has had a population-based policy for sodium reduction anchored on partnership and regulation of the food industry and consumer education via mass media. This has resulted in a $40 \%$ decrease in population sodium consumption, a decrease of more than $10 \mathrm{~mm} \mathrm{Hg}$ in blood pressure and a reduction of $70 \%$ in mortality from stroke and coronary artery disease (Figure 1). ${ }^{10}$ The concurrent improvement in hypertension management during this period probably contributed to the outcomes, but the hypertension treatment and control rates remain unimpressive. ${ }^{22}$

\section{Food labelling}

Food labelling is another key strategy for sodium reduction. It has been used in a few countries and has been particularly successful in Finland and the United Kingdom. ${ }^{10,17}$ Simple and effective consumer-friendly labelling indicating sodium content in processed foods by use of a colour system (red for high salt content, amber for medium salt and green for low salt) is being implemented in several UK food chains. These and other concurrent efforts in the UK have resulted in a reduction of the average population intake of sodium from $3800 \mathrm{mg}$ in 2004 to $3440 \mathrm{mg}$ in $2008 .{ }^{17}$

\section{Collaboration with the food industry}

The reductions achieved in Finland ${ }^{10}$ and more recently in the $\mathrm{UK}^{17}$ and France ${ }^{16}$ were, in part, a result of forging successful collaborative partnerships with the food industry. This strategy is being used in the Canadian effort to reduce sodium as well. ${ }^{23}$

In the UK, voluntary action by the food industry in response to specific timelines and targets for sodium reduction in specific foods set by the Food Standards Agency has resulted in up to a $30 \%$ sodium reduction in foods without impacting taste, and further reductions are planned. ${ }^{17}$ Similarly, in France the bakery sector has reduced sodium in their products with little consumer complaint. ${ }^{16}$

\section{Product reformulation}

In Canada, the food industry has made changes to reduce sodium in soups, breads and other products. In the UK, further product changes are planned after a successful reduction achieved in supermarket foods without affecting consumer taste and preference. . $^{17,23}$

\section{Public education}

Consumer education is very effective, as has been shown in Finland ${ }^{10}$ and the UK. Major public education efforts in the UK by the government and nongovernmental agencies has resulted in increased consumer awareness, with one-third of the population being aware of the need to reduce sodium intake to the recommended level of $2400 \mathrm{mg}$ or less. ${ }^{17}$

\section{Salt substitution}

Salt substitution is another strategy that has been found to lower blood pressure. This strategy has been effective in Finland, where usual table salt was largely replaced by low sodium potassium-enriched Pansalt (Oriola Oy). ${ }^{10}$ In China, substitution of the salt used in domestic cooking with a lowsodium alternative lowered average systolic blood pressure by $5.4 \mathrm{~mm} \mathrm{Hg}$ in the population. ${ }^{24} \mathrm{~A}$ cluster randomized trial among elderly Taiwanese people in which regular salt was substituted with a low-sodium salt markedly reduced cardiovascular events. ${ }^{9}$ Salt substitution may be a cost-effective strategy in developing countries where the principal source of sodium in the diet is salt added during domestic cooking.

In Canada, the Sodium Working Group, formed by the government in 2007 with support from the food and health sectors, will oversee a reduction in dietary sodium that is in keeping with the Canadian and American Dietary Reference Intakes. This working group has held public consultations and received input from stakeholders. Dietary sodium-reduction strategies are under development. Further, many provincial governments are planning regulations and policies to reduce dietary sodium in areas within provincial jurisdiction (e.g., food served in schools). The federal government is also considering changes to food labelling regulations. This provides an opportunity for health care professionals to lobby for food labels that can be read and easily understood by the public.

\section{Interventions at levels other than government}

\section{Supportive environments for sodium reduction}

Links between living and working conditions and sodium intake have not been extensively studied, but the influence of social and environmental factors on diet is well established. Urbanization has had profound changes in dietary habits worldwide and has increased access to processed and prepared food. ${ }^{25}$ With increases in working hours and women in the workforce, demand for convenient processed foods has gone up. ${ }^{26}$ Portion sizes, snacking and fast-food consumption are increasing against a background of far from optimal levels of fruit and vegetable intake..$^{27-29}$ As sodium is a ubiquitous part of most processed foods, factors influencing these dietary 
changes are probably contributing markedly to the current high levels of sodium consumption.

Studies have found positive associations between the built environment and obesity in the US, with people living in poor neighbourhoods compared with those in more affluent neighbourhoods being more likely to consume unhealthy caloriedense salty foods. ${ }^{30}$ Unhealthy food choices and convenience foods containing high levels of sodium are typically more accessible and less expensive than lower sodium and healthier alternatives. These disparities in access, availability and price underscore the need for comprehensive reductions in sodium levels across all classes of manufactured foods and meals prepared for purchase.

\section{Community action to reduce sodium intake}

Community organizations are important stakeholders in sodium-reduction initiatives. They can identify key opinion leaders or groups in the community who can effectively lead efforts to increase sodium awareness with appropriate culturally adapted messages highlighting the detrimental health effects of excess dietary sodium. They may also initiate efforts to lobby policy makers to introduce controls on the addition of sodium to the food supply. ${ }^{16}$ In Finland, homemakers' organizations have facilitated the development, distribution and widespread use of healthy low-sodium easy-to-make recipes in their communities. ${ }^{31}$ Some Canadian communities have formed partnerships to promote health and have included sodium-reduction initiatives.

Table 1. Comparison and evaluation of sodium reduction strategies in selected countries

\begin{tabular}{|c|c|c|c|c|c|c|c|}
\hline Country & $\begin{array}{c}\text { Regulation } \\
\text { of food } \\
\text { industry }\end{array}$ & $\begin{array}{l}\text { Food } \\
\text { labelling }\end{array}$ & $\begin{array}{l}\text { Collaboration } \\
\text { with food } \\
\text { industry }\end{array}$ & $\begin{array}{c}\text { Voluntary } \\
\text { action by } \\
\text { food industry }\end{array}$ & $\begin{array}{l}\text { Product } \\
\text { reformulation }\end{array}$ & $\begin{array}{l}\text { Public } \\
\text { education }\end{array}$ & $\begin{array}{c}\text { Comments on strategies and changes } \\
\text { in population sodium intake }\end{array}$ \\
\hline Finland & Yes & Yes & Yes & Yes & Yes & Yes & $\begin{array}{l}\text { - Government regulation and } \\
\text { implementation of food labeling with } \\
\text { high sodium content warning } \\
\text { - Replacement of usual salt with } \\
\text { potassium-enriched Pansalt } \\
\text { - Strong media campaigns to increase } \\
\text { public awareness } \\
\text { - Sodium intake decreased from } 5600 \text { mg } \\
\text { in } 1972 \text { to } 3200 \text { mg in } 2002\end{array}$ \\
\hline $\begin{array}{l}\text { United } \\
\text { States }\end{array}$ & No & Yes & No & Yes & No & Yes & $\begin{array}{l}\text { - Consistent advice from all health care } \\
\text { bodies since the } 1980 \text { s and call for } \\
\text { sodium reduction by the American } \\
\text { Medical Association in } 2007 \\
\text { - No reduction has taken place } \\
\text { - Sodium intake increased from } 3329 \text { mg } \\
\text { in } 2001 / 02 \text { to } 3436 \text { mg in } 2005 / 06\end{array}$ \\
\hline $\begin{array}{l}\text { United } \\
\text { Kingdom }\end{array}$ & No & Yes & Yes & Yes & Yes & Yes & $\begin{array}{l}\text { - Collaborative effort with food industry } \\
\text { for targeted sodium reduction in specific } \\
\text { groups of foods under the oversight of } \\
\text { the Food Standards Agency } \\
\text { - Ongoing monitoring and evaluation of } \\
\text { population intake } \\
\text { - Public campaigns to increase public } \\
\text { awareness and simple consumer-friendly } \\
\text { labelling strategy } \\
\text { - Sodium intake decreased from } 3800 \text { mg } \\
\text { in } 2004 \text { to } 3440 \text { mg in } 2008\end{array}$ \\
\hline Canada & No & Yes & Yes & Yes & Yes & Yes & $\begin{array}{l}\text { - Early voluntary reductions by food } \\
\text { industry combined with public education } \\
\text { and labelling had no impact on sodium } \\
\text { intake from processed foods } \\
\text { - Too early to access the more recent } \\
\text { collaborative effort }\end{array}$ \\
\hline France & No & Optional & Yes & Yes & Yes & Yes & $\begin{array}{l}\text { - Efforts initiated since } 2004 \\
\text { - Optional sodium labelling being } \\
\text { developed } \\
\text { - Limited public education in which } \\
\text { sodium reduction is the main message is } \\
\text { done through the National Nutrition } \\
\text { and Health Program } \\
\text { - Not much change to date except in the } \\
\text { bakery sector where } 33 \% \text { of bakers claim } \\
\text { to have reduced sodium }\end{array}$ \\
\hline
\end{tabular}




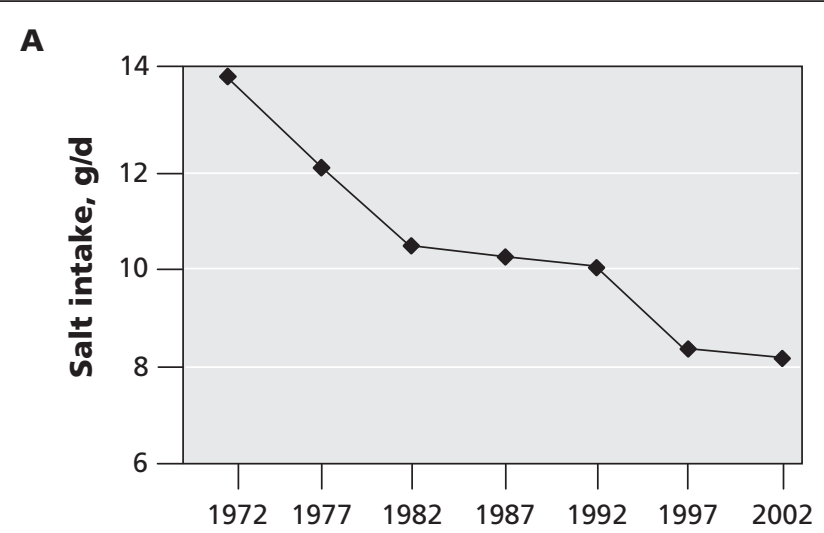

B

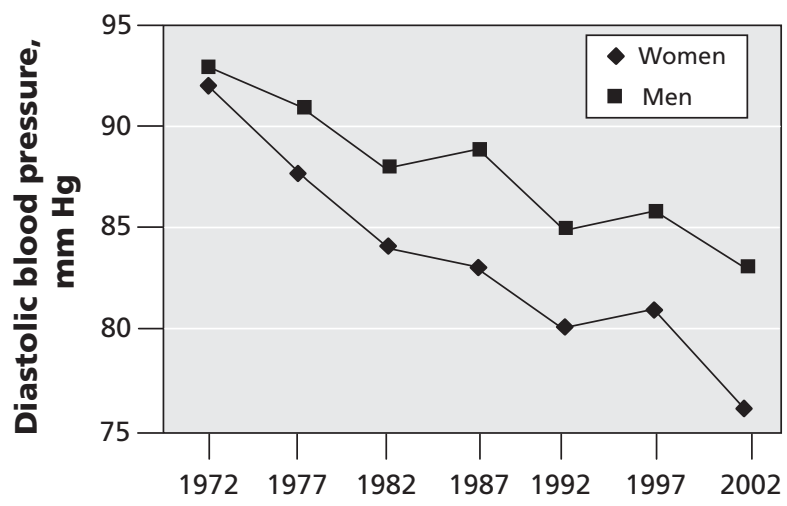

C

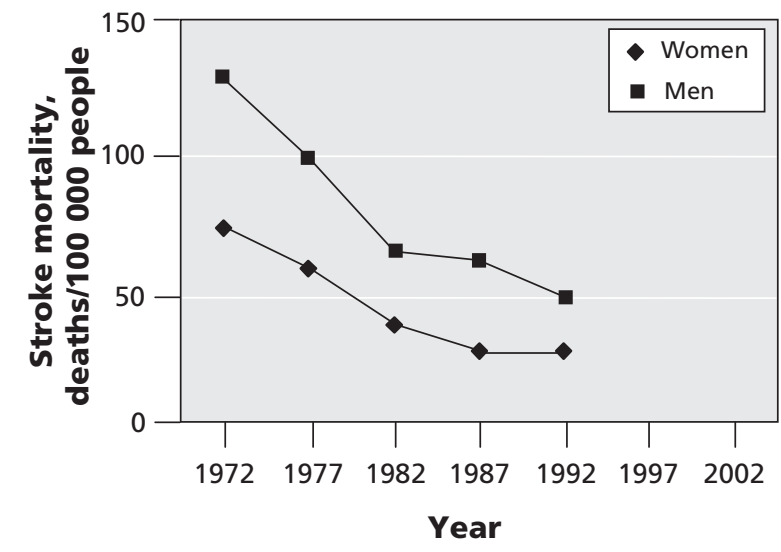

Figure 1: Reductions in salt intake (A), blood pressure (B) and stroke mortality (C) in Finland. Reproduced with permission from Nature Publishing Group..$^{32}$

\section{Enabling individuals to make better food choices}

Increasing individual awareness and knowledge are critical factors in enabling healthy food choices and in building support for policy changes in the individuals' environment. Informed consumers also have an impact by creating a demand for lower-sodium food products and restaurant meals. Effective awareness strategies include targeted health education using the mass media. Consumer friendly labelling to identify low-sodium food products, in-store advertisement and promotion of healthy foods, as well as purchase incentives for low-sodium foods can also help individuals to make changes in buying behaviour and exercise healthy choices. ${ }^{16}$

Health organizations in Canada, including Blood Pressure Canada, the Canadian Stroke Network and Dieticians of Canada are producing standardized educational material for patients, the public and health care professionals on the health risks of high dietary sodium and what consumers can do to reduce dietary sodium. Resources targeted at the public and health care professionals are available at www.sodium101.ca and www.lower sodium.ca. The Canadian Stroke Network, the Heart and Stroke Foundation of Canada and other organizations have supported several media releases on dietary sodium and health. The Heart and Stroke Foundation has also recently revised its Health Check food labelling program to require lower sodium in food products to acquire and sustain the Health Check label.

\section{Reorienting the health sector}

Health care professionals, including physicians, need to counsel patients about the health risks of excess sodium intake and how to reduce consumption. Therefore, it is necessary to incorporate sodium-reduction strategies and their importance in cardiovascular disease prevention into professional training curricula. ${ }^{16} \mathrm{An}$ interdisciplinary approach that includes assessment of sodium intake during patient encounters and advice on sodiumreduction strategies should become standard practice in hypertension management. While time constraints in clinics make this difficult, short questionnaires such as those developed by Charlton and colleagues, ${ }^{32}$ suitably adapted to local foods, could be used. Evidence suggests that brief individual counselling in primary care by nurses that includes messaging on sodium can be effective in increasing intake of vegetables and fruits. ${ }^{33}$ Furthermore, food served within the health sector should be consistent with current dietary sodium recommendations.

Conflicts of interest with the food industry are relevant to sodium reduction policies. In the absence of awareness, effective controls and oversight, the food industry is able to exert influence on food policy and, consequently, on population health. ${ }^{34}$ Public health would be greatly benefited by reforms in the health sector to ensure more transparent interactions between the food industry and health care professionals and by the introduction of measures to reduce commercial influence on public health policies and health care professional organizations.

\section{Monitoring and evaluating sodium intake}

Assessing the baseline intake of sodium in a population is a crucial first step in evaluating the effectiveness of sodiumreduction programs. The principal methods are by dietary recall and measurement of sodium in 24-hour urinary excretion tests. The latter is more reliable but is logistically difficult, while the former does not account for sodium added during cooking or at the table. Furthermore, given considerable intraindividual variability in daily sodium intake, these methods do not accurately represent usual intake for the individual, but they can be used to assess usual population sodium intake. ${ }^{16}$ 


\section{Gaps in knowledge}

The full extent of the population health benefits that can be expected from sodium reduction, particularly for noncardiovascular outcomes, is unclear given the lack of evidence from randomized controlled trials. For example, greater health benefits were observed in the post-trial follow-up of participants in the Trials of Hypertension Prevention study and in a cluster randomized trial in Taiwan than what was predicted by the reduction in blood pressure alone. Potential improvements in asthma and osteoporosis with sodium reduction have not been adequately assessed. ${ }^{8,9}$

Which specific policies result in optimum reductions in population sodium intake (e.g., a voluntary approach by the food industry, government legislation or a combination of these) has not been established. From a food technology perspective, it is unclear how quickly and extensively sodium can be reduced in foods without impacting consumer appeal. Evidence is lacking with regard to what works the best in terms of social marketing and public-education strategies, health care professional advice and effective food labelling systems to inform the public and improve awareness of the harmful effects of sodium.

\section{Recommendations}

Reducing dietary sodium is a major public health priority and demands effective action both by governments and nongovernmental organizations interested in improving population health. Although voluntary action by the food industry may be the preferred option to initiate sodium reduction, its absence calls for governments to use their regulatory capacity to bring about change. Governments should also make simple, easy to understand food labelling mandatory and should initiate and support effective public education campaigns to improve awareness about the deleterious effects of sodium on health. Furthermore, governments and health policymakers should set and monitor achievable targets and timelines for sodium reduction. Nongovernmental organizations should act as pressure groups and lobby the food industry to take action and the government to make sodium-reduction policies a priority. They should also partner with governments in public education directed at increasing public awareness which will create enabling conditions for sodium reduction. Health care professionals, in addition to counselling patients about the risks associated with excess sodium intake and ways to reduce it, should form partnerships to advocate and lobby for implementing sodium reduction policies.

\section{This article has been peer reviewed.}

Competing interests: None declared for Sailesh Mohan and Kevin Willis. Norm Campbell has received honoraria for advising and speaking from most major pharmaceutical companies that produce antihypertensive drugs.

Contributors: Sailesh Mohan designed the analysis, drafted and critically revised the article. Norm Campbell and Kevin Willis contributed to the analysis and critical revision of the article. All the authors gave final approval of the version to be published.

Acknowledgements: Sailesh Mohan is supported by the Canadian Institutes of Health Research Canada HOPE Fellowship. Norm Campbell is supported by the Canadian Institutes of Health Research Canada Chair in Hypertension Prevention and Control.

\section{REFERENCES}

1. Lawes CM, Vander Hoorn S, Rodgers A; International Society of Hypertension. Global burden of blood-pressure-related disease, 2001. Lancet 2008:371:1513-8.

2. de Wardener HE, MacGregor GA. Harmful effects of dietary salt in addition to hypertension. J Hum Hypertens 2002;16:213-23.

3. Joffres MR, Campbell NRC, Manns B, et al. Estimate of the benefits of a population-based reduction in dietary sodium additives on hypertension and its related health care costs in Canada. Can J Cardiol 2007;23:437-43.

4. Cook NR, Cohen J, Hebert PR, et al. Implications of small reductions in diastolic blood pressure for primary prevention. Arch Intern Med 1995;155:701-9.

5. Ottawa Charter for Health Promotion. Ottawa $(\mathrm{ON})$ : The World Health Organization; 1986. Available: www.who.int/healthpromotion/conferences/previous/ottawa /en/ (accessed 2009 Aug. 25).

6. Kearney PM, Whelton M, Reynolds K, et al. Global burden of hypertension: analysis of worldwide data. Lancet 2005;365:217-23.

7. Geleijnse JM, Grobbee DE, Kok FJ. Impact of dietary and lifestyle factors on the prevalence of hypertension in Western populations. J Hum Hypertens 2005;19:S1-4.

8. Cook NR, Cutler JA, Obarzanek E, et al. Long term effects of dietary sodium reduction on cardiovascular disease outcomes: observational follow-up of the trials of hypertension prevention (TOHP). BMJ 2007;334:885.

9. Chang HY, Hu YW, Yue CS, et al. Effect of potassium enriched salt on cardiovascular mortality and medical expenses of elderly men. Am J Clin Nutr 2006;83:1289-96.

10. Karppanen H, Mervaala E. Sodium intake and hypertension. Prog Cardiovasc Dis 2006;49:59-75.

11. Asaria P, Chisholm D, Mathers C, et al. Chronic disease prevention: health effects and financial costs of strategies to reduce salt intake and control tobacco use. Lancet 2007;370:2044-53

12. Hemmelgarn BR, Chen G, Walker R, et al. Trends in antihypertensive drug prescriptions and physician visits in Canada between 1996 and 2006. Can J Cardiol 2008;24:507-12.

13. Neutel CI, Campbell NR; Canadian Hypertension Society. Changes in lifestyle after hypertension diagnosis in Canada. Can J Cardiol 2008;24:199-204.

14. Penz ED, Joffres MR, Campbell NR. Reducing dietary sodium and decreases in cardiovascular disease in Canada. Can J Cardiol 2008;24:497-501.

15. Garriguet D. Sodium consumption at all ages. Health Rep 2007;18:47-52.

16. Reducing salt intake in populations: report of a WHO forum and technical meeting. 2006 October 5-7; Paris (France): WHO Forum on Reducing Salt Intake in Populations. Available: www.who.int/dietphysicalactivity/Salt_Report_VC april07.pdf (accessed 2009 July 14).

17. He FJ, MacGregor GA. A comprehensive review on salt and health and current experience of worldwide salt reduction programmes. J Hum Hypertens 2009;23:363-84.

18. Institute of Medicine. Dietary reference intakes: water, potassium, sodium chloride, and sulfate. 1st ed. Washington (DC): National Academy Press; 2004.

19. He FJ, MacGregor GA. How far should salt intake be reduced? Hypertension 2003:42:1093-9.

20. Mattes RD, Donnelly D. Relative contributions of dietary sodium sources. J Am Coll Nutr 1991;10:383-93.

21. Karppanen H, Karppanen P, Mervaala E. Why and how to implement sodium, potassium, calcium, and magnesium changes in food items and diets? J Hum Hypertens 2005;19:S10-9.

22. Kastarinen M, Antikainen R, Peltonen M, et al Prevalence, awareness and treatment of hypertension in Finland during 1982-2007. J Hypertens 2009;27:1552-9.

23. Campbell N. Health check program. CMAJ 2008;178:1186-7.

24. China Salt Substitute Study Collaborative Group. Salt substitution: a low-cost strategy for blood pressure control among rural Chinese. A randomized, controlled trial. J Hypertens 2007;25:2011-8.

25. Popkin BM, Duffey K, Gordon-Larsen P. Environmental influences on food choice, physical activity and energy balance. Physiol Behav 2005;86:603-13.

26. Popkin BM, Gordon-Larsen P. The nutrition transition: worldwide obesity dynamics and their determinants. Int J Obes Relat Metab Disord 2004;28:S2-9.

27. Nielsen SJ, Popkin BM. Patterns and trends in food portion sizes, 1977-1998 JAMA 2003;289:450-3

28. Zizza C, Siega-Riz AM, Popkin BM. Significant increase in young adults' snacking between 1977-1978 and 1994-1996 represents a cause for concern! Prev Med 2001;32:303-10.

29. Jahns L, Siega-Riz AM, Popkin BM. The increasing prevalence of snacking among US children from 1977 to 1996. J Pediatr 2001;138:493-8.

30. Papas MA, Alberg AJ, Ewing R, et al. The built environment and obesity. Epidemiol Rev 2007;29:129-43

31. Pekka P, Pietinen P, Uusitalo U. Influencing public nutrition for non-communicable disease prevention: from community intervention to national programmeexperiences from Finland. Public Health Nutr 2002;5:245-51.

32. Charlton KE, Steyn K, Levitt NS, et al. Development and validation of a short questionnaire to assess sodium intake. Public Health Nutr 2008;11:83-94.

33. Steptoe A, Perkins-Porras L, McKay C, et al. Behavioural counselling to increase consumption of fruit and vegetables in low income adults: randomised trial. $B M J$ 2003;326:855.

34. Nestle M. Food politics: how the food industry influences nutrition and health. Berkely (CA): University of California Press; 2007.

Correspondence to: Dr. Norm R.C. Campbell, University of Calgary, 3330 Hospital Dr. NW, Calgary AB T2N 4N1;

fax 403 283-6151; ncampbel@ucalgary.ca 